Check for updates

Cite this: RSC Adv., 2020, 10, 41013

\title{
Study of near-infrared light-induced excitation of upconversion nanoparticles as a vector for non- viral DNA delivery $\dagger$
}

\author{
Jen-Hsuan Wang, (D) ${ }^{a}$ Hsin-Yu Chen, ${ }^{a}$ Ching-Cheng Chuang ${ }^{\text {ab }}$ \\ and Jung-Chih Chen (ID *abc
}

\begin{abstract}
Clinical requirements have necessitated the development of biomedical nanomaterials that can be implanted into tissues or bodies. Physiological regulation can be achieved in these nanomaterials through external light. The combination of nanomaterials with infrared optics can be termed optogenetics. The low autofluorescence of upconversion nanoparticles (UCNPs) has several applications in the biological field. For optogenetics applications, UCNPs with high fluorescence performance and photostability can solve the penetration depth problem. $\mathrm{NaYF}_{4}: \mathrm{Yb}, \mathrm{Tm}$ nanocrystals with controllable sizes, shapes, and compositions were synthesized using a rapid coprecipitation method in organic solvent. UCNPs using single crystal nanoparticles provide higher chemical stability than those using amorphous phase. However, because UCNPs are usually capped with hydrophobic ligands, it is particularly important to prepare biocompatible UCNPs with specific molecular recognition capabilities. Surface modification and subsequent functionalization are essential for the application of inorganic nanomaterials in the biological environment and are arousing increasing research interest. Due to the high biocompatibility and high loading of materials, mesoporous silica and amine groups were selected as the best candidates. Expression of plasmid DNA in vivo and transfection efficiency were determined by fluorescence microscopy and flow cytometry. The MTT assay was used to evaluate the particle biocompatibility; the results showed that $\mathrm{UCNP} \mathrm{amSiO}_{2}$ has great biocompatibility. Additionally, at neutral $\mathrm{pH}$, the cell surface is negatively charged. Therefore, the surface is functionalized with amino groups and can be electrostatically bound to DNA. Finally, UCNP $\left(\mathrm{mSiO}_{2}-\mathrm{NH}_{2}\right.$ as a vector was applied in live cells by loading DNA; according to the results, DNA-UCNPs were successfully transfected in the primary cells, and $\mathrm{NaYF}_{4}: \mathrm{Yb}, \mathrm{TmamSiO}{ }_{2}-\mathrm{NH}_{2}-\mathrm{DNA}$ were observed to have good transfection efficiency by flow cytometry. It is expected that this work will provide a different method from the traditional adenovirus method and improve the immune response and side effects caused by adenovirus.
\end{abstract}

Received 19th June 2020

DOI: 10.1039/dOra05385f

rsc.li/rsc-advances

\section{Introduction}

Lanthanide-doped rare-earth upconversion is a popular research field because nanocrystals exhibit unique properties; they can convert low-energy near-infrared (NIR) light to highenergy visible light, ${ }^{\mathbf{1 - 5}}$ particularly when the nanocrystals are doped with sensitizers and activators. The sensitizers can absorb the NIR light, and the energy is transferred to the activators. ${ }^{6-8}$ NIR light has better penetration depth than visible

\footnotetext{
anstitute of Biomedical Engineering, National Chiao Tung University, HsinChu, 30010 Taiwan, Republic of China. E-mail: george@nctu.edu.tw

${ }^{b}$ Department of Electrical and Computer Engineering, National Chiao Tung University, HsinChu, 30010 Taiwan, Republic of China

${ }^{c}$ Department of Biological Science and Technology, National Chiao Tung University, HsinChu, 30010 Taiwan, Republic of China

$\dagger$ Electronic supplementary information (ESI) available. See DOI: 10.1039/d0ra05385f
}

light and can be used as a non-invasive treatment. UCNPs can be excited by the high penetration depth of NIR light; also, they possess a low-autofluorescence background ${ }^{9-11}$ and high biocompatibility ${ }^{12-14}$ for various biological applications. ${ }^{15-19}$

One of the most advanced technologies in neuroscience, optogenetics combines optical and genetic techniques. ${ }^{\mathbf{2 0 - 2 5}}$ Using this technique, a light can be used to control a single neuron cell. Optogenetics technology can be spatially regulated to single-cell size and millisecond-level precision, unlike current techniques that only use voltage and current to control the neuron membrane potential. For example, during the process of isolation of light-sensitive ion channel proteins from cyanobacteria, ${ }^{26-28}$ ion channel channelrhodopsin-2 (ChR2) dominates through blue light at the $470 \mathrm{~nm}$ band. However, visible light cannot attain the required penetration depth to achieve non-invasive isolation. Therefore, it is necessary to implant an invasive fiber as a light source to excite the channel proteins. However, the installation of most invasive systems is 
highly complex. Therefore, the visible-light penetration depth problem should be resolved. Nanoparticles with special features provide opportunities and challenges. The nanoparticles currently in clinical trials represent promising non-invasive technology for appropriate applications (e.g., thermal heating $^{29}$ and DNA carriers ${ }^{30}$ ) and can provide better penetration ability than visible light. ${ }^{31-34}$ However, NIR cannot regulate light-sensitive channel proteins. Therefore, we developed nanocrystals that can convert NIR light into blue light to isolate channel proteins using a non-invasive method.

Most DNA transfection methods use liposomes or nanoparticles as a vector. After the DNA is delivered into the cell, the liposome or nanoparticle has no effect. However, we used UCNPs as a vector to carry DNA with ChR2 (a channel protein) into the cell. When the DNA is successfully transfected, a lightsensitive protein ion channel will be formed on the cell membrane. When irradiated with $808 \mathrm{~nm}$ NIR light, the UCNPs will emit blue light, causing ChR2 on the cell membrane to be stimulated by blue light to open non-specific cation channels, causing cell depolarization. ${ }^{35,36}$

$\mathrm{NaYF}_{4}$ is the main body of a common upconversion nanoparticle matrix material; it has two different $\mathrm{NaYF}_{4}$ phase structures (hexagonal phase ( $\beta$-phase) and cubic phase $(\alpha$ phase)). The different phases of the UCNPs can be switched by annealing between the cubic phase and the hexagonal phase. Hexagonal $\mathrm{NaYF}_{4}$-based upconversion nanocrystals with sensitizers and activators are doped into the host to achieve efficient photon upconversion. ${ }^{37-39}$ We used X-ray diffraction (XRD) and transmission electron microscopy (TEM) to identify the structure of the particle; it is a hexagonal phase structure. $\mathrm{Yb}^{3+}$ is commonly selected as a sensitizer to absorb the excitation energy from NIR light. Finally, the energy is transferred to the activator through the energy transfer upconversion method. ${ }^{\mathbf{4 0}}$ Theoretically, increasing the sensitizer concentration can enhance the absorption of energy from the excitation source, thus increasing the fluorescence intensity. However, with increasing $\mathrm{Yb}^{3+}$ concentration, the size of the nanocrystals can increase to $100 \mathrm{~nm}$. Because of the nucleation rate, ${ }^{41-43}$ the $\mathrm{Yb}^{3+}$ concentration-induced increase in the size of the nanocrystals hinders the upconversion of the nanocrystals. Therefore, smallsized UCNPs with excellent lifetimes are preferred, especially in the optogenetics field. The coprecipitation method is a typical treatment to obtain various morphologies and particle sizes in different organic solvents. This method is suitable to synthesize $\mathrm{NaYF}_{4}$ rare-earth inorganic materials with different ion concentrations. ${ }^{\mathbf{4 4 , 4 5}} \mathrm{NaYF}_{4}$ nanocrystals are synthesized using the coprecipitation method in organic solvents. Thus, the surface of the nanocrystals is covered by hydrophobic groups (such as oleic acid and 1-octadecene), which restrict their optogenetic and cell applications.

Surface hydrophilic modification is necessary before biological application, and nanocrystal stability is crucial. The use of mesoporous silica-coated lanthanide-doped upconversion nanoparticles (UCNP@mSiO $\mathrm{M}_{2}$ ) results in simultaneous gene delivery and optogenetic application of nanocomposites. ${ }^{\mathbf{4 6 , 4 7}}$ This improves the surface properties of the nanocomposites for functionalization, bioconjugation, and dispersibility in water. ${ }^{30}$
Mesoporous silica with monodispersed sizes, uniform shapes, and high biocompatibility can minimize fluorescence quenching with surface absorbent organic ligands. ${ }^{48}$

After $\mathrm{Yb}^{3+}$ absorbs $980 \mathrm{~nm}$ near-infrared light, it uses energy conversion to cause $\mathrm{Tm}^{3+}$ to absorb energy and emit blue light. Photoluminescence spectrometry (PL) and UV/Vis spectrophotometry (UV-Vis) are used to observe the influence of the light emission spectra and absorption spectra of mesoporous silicacoated lanthanide-doped upconversion nanoparticles.

Jie Yu's research team systematically studied the biological distribution, excretion, and toxicity of PEI@UCNPs through different administration routes. Intravenous injection of PEI@UCNPs is mainly concentrated in the spleen, and its excretion rate is slower than those of other organs; meanwhile, after intramuscular injection of PEI@UCNPs, the UCNPs are continuously removed from the liver and spleen within 30 days. This study shows that PEI@UCNPs have low toxicity, reduced accumulation in the RES (reticuloendothelial system), and gradual excretion through feces after intravenous injection. In terms of stability testing, PEI@UCNPs were shaken at $37^{\circ} \mathrm{C}$ for $24 \mathrm{~h}$, and no change in the crystal phase was observed. Therefore, it was concluded that PEI@UCNPs have good stability in the physiological environment. ${ }^{49}$

Currently, the most popular means of delivering optogenetics tools is viral vectors. ${ }^{50}$ When the virus successfully transfects the target cell, the light-sensitive channel protein is expressed. However, one serious problem with adenovirus transfection is the immune response in the body, which will eliminate the virus-infected cells, resulting in relatively short gene expression. Therefore, when an organism needs to express a specific gene, a very large amount of adenovirus must be transfected, which is highly likely to cause a serious inflammatory reaction or side effect. ${ }^{51}$ Compared with viral systems, non-viral systems show the advantages of low toxicity, low immunogenicity, and the ability to deliver larger DNA fragments multiple times. However, improving transfection efficiency is a substantial challenge for non-viral transfection vectors. ${ }^{30,52}$ Owing to these factors, non-viral transfection is currently popular. However, transfection efficiency is a great challenge to non-viral transfection vectors.

In this study, we systemically report the fluorescence mechanisms of various rare-earth ion molar ratios. The details of the sizes and morphologies of the synthesized single crystals of $\beta-\mathrm{NaYF}_{4}$ were verified through transmission electron microscopy (TEM) with selected area diffraction. The performance of single-crystal $\beta-\mathrm{NaYF}_{4}$ was examined. Additionally, mesoporous silica and amino groups were synthesized for application in optogenetics in the future; $\mathrm{NaYF}_{4}$ :$\mathrm{Yb}$,Tm@mSiO $\mathrm{SH}_{2}-\mathrm{NH}_{2}$ upconversion nanoparticles were used and correlated with pcDNA3.1/hChR2(H134R)-mCherry. Biocompatibility in the primary cell was examined using the $3-(4,5-$ dimethylthiazol-2-yl)-2,5-diphenyltetrazolium bromide (MTT) method, and the efficiency of the DNA-UCNPs delivery system in primary cells was studied through fluorescence microscopy and flow cytometry. The current research demonstrates the potential of UCNPs to deliver DNA safely and efficiently. 


\section{Materials and methods}

\section{Materials}

Yttrium(III) acetate hydrate (99.9\%, ALFA Aesar), ytterbium(III) acetate hydrate (99.9\%, ALFA Aesar), thulium(III) acetate hydrate (99.9\%, ALFA Aesar), oleic acid (90\%, Sigma-Aldrich), 1-octadecene (90\%, ACROS), ammonium fluoride (98\%, Merck), sodium hydroxide (98\%, Merck), cyclohexane (99\%, JT Baker), tetraethyl orthosilicate $(99.0 \%$, Sigma-Aldrich), methanol (99.9\%, Fisher), hexadecyltrimethylammonium chloride ( $\geq 98.0 \%$, Sigma-Aldrich), hydrochloric acid (37\%, SigmaAldrich), polyethylenimine (branched, $M_{\mathrm{w}} 70000,30 \% \mathrm{w} / \mathrm{v}$ aq., Polysciences), phosphate buffered saline (powder, pH 7.4, Sigma-Aldrich), trypsin-EDTA (0.5\%, no phenol red, Thermo Fisher Scientific), and ethanol (99.5\%, Sigma-Aldrich) were used in the experiments. All chemicals were of analytical grade and were used as received without further purification.

\section{Synthesis of $\mathrm{NaYF}_{4}: \mathrm{Yb}, \mathrm{Tm}$ as a core structure}

Core UCNPs were synthesized using the coprecipitation method. In this study, $4 \mathrm{~mL}$ aqueous solution containing yttrium acetate hydrate (88\%), ytterbium acetate hydrate $(20 \%)$, and thulium acetate hydrate (2\%) was mixed with oleic acid and 1-octadecene and stirred for $30 \mathrm{~min}$. The mixture was heated to $150{ }^{\circ} \mathrm{C}$ for $1 \mathrm{~h}$ to form a yellow solution. After cooling the solution, $2 \mathrm{~mL}$ of sodium hydroxide and $7.9 \mathrm{~mL}$ of ammonium fluoride were added to the solution and stirred for $1 \mathrm{~h}$. Then, the solution was heated at $110{ }^{\circ} \mathrm{C}$ for $20 \mathrm{~min}$ to remove methanol. Next, the solution was heated to $310{ }^{\circ} \mathrm{C}$ for 25 min under argon atmosphere. Finally, the solution was collected through centrifugation for $10 \mathrm{~min}$ and stocked in cyclohexane.

\section{Synthesis of $\mathrm{NaYF}_{4}: \mathrm{Yb}, \mathrm{Tm} @ \mathrm{NaYF}_{4}: \mathrm{Yb}, \mathrm{Nd}$ as a core/shell structure}

Core/shell UCNPs were synthesized using the coprecipitation method. In this study, $3.4 \mathrm{~mL}$ aqueous solution containing yttrium acetate hydrate (88\%), ytterbium acetate hydrate $(20 \%)$, and neodymium acetate hydrate $(20 \%)$ was mixed with oleic acid and 1-octadecene and stirred for $30 \mathrm{~min}$. The mixture was heated to $150{ }^{\circ} \mathrm{C}$ for $1 \mathrm{~h}$. After cooling the solution, $1.7 \mathrm{~mL}$ of sodium hydroxide, $6.8 \mathrm{~mL}$ of ammonium fluoride, and all of $\mathrm{NaYF}_{4}: \mathrm{Yb}, \mathrm{Tm}$ solution (around 230-240 $\mu \mathrm{g}$ ) were added to the solution and stirred for $1 \mathrm{~h}$. Then, the solution was heated at $110{ }^{\circ} \mathrm{C}$ for $20 \mathrm{~min}$ to remove methanol. Next, the solution was heated to $305{ }^{\circ} \mathrm{C}$ for 90 min under argon atmosphere. Finally, the solution was collected through centrifugation for $10 \mathrm{~min}$ and stocked in cyclohexane.

\section{Synthesis of the mesoporous silica shell of the UCNPs}

Mesoporous shells of the UCNPs were synthesized using tetraethyl orthosilicate (TEOS) and hexadecyltrimethylammonium chloride (CTAC) as templates. UCNPs with cyclohexane $(1 \mathrm{~mL})$ mixed with $8 \mathrm{~mL}$ CTAC $(0.06 \mathrm{M})$ was stirred for $1 \mathrm{~h}$. The solution was heated to $80{ }^{\circ} \mathrm{C}$ for $30 \mathrm{~min}$ to remove cyclohexane and sonicated for $30 \mathrm{~min}$ with $30 \mathrm{~mL}$ deionized water. The resultant solution was mixed with $1.4 \mathrm{~mL}$ ethanol, and the $\mathrm{pH}$ value was adjusted to $\mathrm{pH} 10$ by adding ammonia water. TEOS was added dropwise to the solution at $35{ }^{\circ} \mathrm{C}$ for $24 \mathrm{~h}$. Finally, the solution was collected through centrifugation at $10000 \mathrm{rpm}$ for $10 \mathrm{~min}$ and stocked in deionized water. Hydrochloric acid was used to remove the surfactant CTAC to form mesoporous silica shells, and the as-synthesized UCNP@ $\mathrm{mSiO}_{2}(10 \mathrm{mg})$ was transferred to $40 \mathrm{~mL}$ methanol containing $200 \mu \mathrm{L}$ hydrochloric acid at $50{ }^{\circ} \mathrm{C}$ for $24 \mathrm{~h}$. Finally, the resultant solution was collected through centrifugation at $10000 \mathrm{rpm}$ for $10 \mathrm{~min}$ and dispersed in ethanol.

\section{Synthesis of the amino groups of UCNP@mSiO}

UCNP@ $\mathrm{mSiO}_{2}$ was sonicated for $20 \mathrm{~min}$ with $20 \mathrm{~mL}$ ethanol. $2 \mathrm{~mL}$ of polyethylenimine was added, and the mixture was heated to $80{ }^{\circ} \mathrm{C}$ for $3 \mathrm{~h}$. Finally, the resultant solution was collected through centrifugation at $10000 \mathrm{rpm}$ for $10 \mathrm{~min}$ and dispersed in ethanol.

\section{Synthesis of UCNP@mSiO $\mathrm{m}_{2}-\mathrm{NH}_{2}$-DNA}

UCNP@mSiO ${ }_{2}-\mathrm{NH}_{2}$ and plasmid DNA were mixed in phosphate buffered saline (PBS) (1 mg UCNPs per mL PBS) at different ratios $(\mathrm{w} / \mathrm{w})$ at room temperature for $1 \mathrm{~h}$.

\section{Isolation of the primary cardiomyocytes}

The hearts of new-born of Sprague-Dawley (SD) rats (about 2-3 days old) were removed. The hearts were placed in trypsin and shaken at $80 \mathrm{rpm}$ at $4{ }^{\circ} \mathrm{C}$ for $15-20 \mathrm{~h}$. The trypsin was removed, $10 \%$ medium was added, and the mixture was shaken at $75 \mathrm{rpm}$ for $10 \mathrm{~min}$ at $37^{\circ} \mathrm{C}$. The medium was removed. HBSS containing collagenase II was added and shaken for 1 minute. The cells were pipetted and filtered with a filter, then centrifuged at $500 \mathrm{rpm}$ at $4{ }^{\circ} \mathrm{C}$ for $5 \mathrm{~min} .10 \%$ medium was added, and the cells were placed in T75 flasks in a $37{ }^{\circ} \mathrm{C}$ incubator for $1 \mathrm{~h}$. The cells were centrifuged at $500 \mathrm{rpm}$ at $4{ }^{\circ} \mathrm{C}$ for $5 \mathrm{~min}$. The supernatant was removed, $10 \%$ medium was added, the cells were counted, the cell concentration was adjusted to about $2 \times 10^{5}$ cells per $\mathrm{mL}$, and the cells were added to a 24 -well plate and placed in the $37^{\circ} \mathrm{C}$ incubator.

\section{Transfection of primary cells}

pcDNA3.1/hChR2(H134R)-mCherry was used for the transfection of cardiomyocyte cells with the amino-modified UCNPs. The transfection of primary cells with the UCNP@ $\mathrm{mSiO}_{2}-\mathrm{NH}_{2}$-DNA complex solutions remained at the UCNPs/DNA weight ratio of $5: 1(\mathrm{w} / \mathrm{w})$. Transfection was cultured in an incubator with $5 \% \mathrm{CO}_{2}$ at $37{ }^{\circ} \mathrm{C}$ for $48 \mathrm{~h}$. At the end of the incubation, the cells were washed with PBS. The cells were imaged immediately to determine the mCherry fluorescence under a fluorescence microscope (Olympus).

\section{Characterization}

Field emission electron microscopy was conducted using a JEOL 7401 field emission electron microscope at an acceleration voltage of $5 \mathrm{kV}$. High-resolution TEM (HRTEM) was conducted using a JEOL 2010 at an acceleration voltage of $200 \mathrm{kV}$. Powder X-ray diffraction (XRD) data were recorded using 
a Bruker D8 Advance X-ray diffractometer with $\mathrm{Cu} k \alpha$ radiation $(\lambda=1.5406 \AA)$. The binding energy was analyzed using a Thermo Fisher Scientific ESCALAB Xi ${ }^{+}$X-ray photon electron and Auger electron spectroscope. UV-visible-near-infrared spectra were measured using a ChromTech CT-2800 equipped with a Hitachi F-7000 fluorescence spectrophotometer to record the upconversion fluorescence.

\section{Cytotoxicity measurements}

The in vitro cytotoxicities of $\mathrm{UCNP}_{\mathrm{O}} \mathrm{mSiO}_{2}$ were tested through the MTT assay. Primary cardiac myoblast cells were seeded in 96well cell culture plates $\left(4 \times 10^{4}\right.$ cells per well). UCNP@mSiO concentrations of $1000,750,500,250$, and $0 \mu \mathrm{g} \mathrm{mL}{ }^{-1}$ in $100 \mu \mathrm{L}$ fresh medium were added to the wells, and the 96-well plate was cultured in an incubator with $5 \% \mathrm{CO}_{2}$ at $37{ }^{\circ} \mathrm{C}$ for $48 \mathrm{~h}$. After washing with the previous solution, the MTT reagent $\left(0.5 \mathrm{mg} \mathrm{mL}^{-1}\right.$ in $100 \mu \mathrm{L}$ fresh medium) was added to the plate, which was cultured for another $4 \mathrm{~h}$ in an incubator with $5 \% \mathrm{CO}_{2}$ at $37{ }^{\circ} \mathrm{C}$. Finally, the supernatant was removed and $100 \mu \mathrm{L}$ dimethyl sulfoxide was added to the wells. The MTT absorbance $(\lambda=570 \mathrm{~nm})$ of each well was measured by the reader. The cell metabolic activity was computed using the optical contrast-to-control value.

\section{Flow cytometry analysis}

The cells after transfection were washed with PBS and trypsinized by trypsin-EDTA, than centrifuged at $12000 \mathrm{rpm}$. The cellular transfection effectiveness of recombinant plasmid pcDNA3.1/hChR2(H134R)-mCherry was quantified using flow cytometry (ImageStreamX Mark II) under $561 \mathrm{~nm}$ at $200 \mathrm{~mW}$. Flow cytometry measurements were performed with an ISX MkII using ISX500 software.

\section{Data analysis}

Data analysis was carried out using Microsoft ${ }^{\circledR}$ Excel and SPSS. Statistical significance was determined using the paired sample $t$-test, with $P<0.05$ deemed significant.

\section{Results and discussion}

Preparation and characterization of $\beta-\mathrm{NaYF}_{4}$ nanocrystals: in order to examine the application possibilities of UCNPs in optogenetics and biological imaging, oleic acid was used as a stabilizer and was synthesized by the thermal co-precipitation method to observe whether the $\mathrm{NaYF}_{4}: \mathrm{Yb}, \mathrm{Tm}$ nanocrystals are $\beta-\mathrm{NaYF}_{4}: \mathrm{Yb}, \mathrm{Tm}$ with a pure hexagonal structure at different $\mathrm{Yb}^{3+}$ and $\mathrm{Tm}^{3+}$ concentrations. The final products indicated that the transfer of $\alpha-\mathrm{NaYF}_{4}$ (cubic phase) to $\beta-\mathrm{NaYF}_{4}$ (hexagonal phase) nanocrystals requires additional $\mathrm{Na}^{+}$and $\mathrm{F}^{-}$ion doping with high reaction temperature. Therefore, $\mathrm{NaOH}$ and $\mathrm{NH}_{4} \mathrm{~F}$ were used as precursors.

To verify the appropriate delta between the sensitizer and the activator, we compared the intervals of the blue emission intensities at different $\mathrm{Yb}^{3+}$ and $\mathrm{Tm}^{3+}$ concentrations. The intensity for $478 \mathrm{~nm}$ from $\mathrm{NaYF}_{4}: \mathrm{Yb}, \mathrm{Tm}(20 \% / 2 \%)$ increased 1.5 and 1.6 times from those of $\mathrm{NaYF}_{4}: \mathrm{Yb}, \mathrm{Tm}(15 \% / 2 \%)$ and $\mathrm{NaYF}_{4}: \mathrm{Yb}, \mathrm{Tm}(25 \% / 2 \%)$, respectively (Fig. 1). Fig. 1 shows the

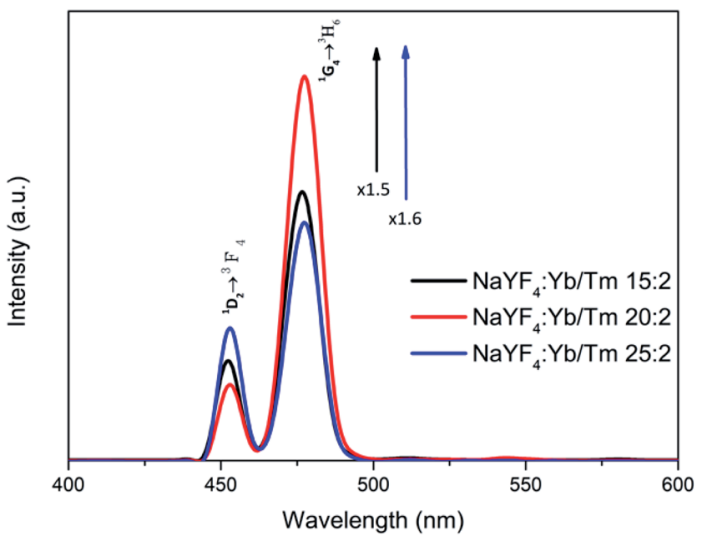

Fig. 1 Photoluminescence spectra of UCNPs with different $\mathrm{Yb}^{3+}$ and $\mathrm{Tm}^{3+}$ concentrations in cyclohexane under $980 \mathrm{~nm}$ excitation $(1 \mathrm{~W}$ $\mathrm{cm}^{-2}$ ).

$450 \mathrm{~nm}$ and $475 \mathrm{~nm}$ emissions resulting from the ${ }^{1} \mathrm{D}_{2} \rightarrow{ }^{3} \mathrm{~F}_{4}$ and ${ }^{1} \mathrm{G}_{4} \rightarrow{ }^{3} \mathrm{H}_{6}$ transitions, respectively. This was attributed to the increase in the amount of the $\mathrm{Tm}^{3+}$ doping, which led to a serious cross-relaxation effect among the activators that resulted in the collapse of the $450 \mathrm{~nm}$ and $475 \mathrm{~nm}$ emissions.

From the SEM results, it can be seen that when $\mathrm{Y}^{3+}$ ion is added to $88 \mathrm{~mol} \%$ (Fig. 2a and b), the particle sizes and shapes are uniform and the hexagonal edges of the nanocrystals appear and sharpen. The luminous efficiency of this structure is much higher than that of the cubic phase ( $\alpha$-phase). The size of the particles will also affect the final light emission efficiency and subsequent DNA transfection efficiency. The crystal size is about $45 \mathrm{~nm}$. After modification, nanoparticles of this size can more easily enter the cell through endocytosis for transfection. The crystal lattice of the nanoplates was revealed through HRTEM to be hexagonal phase with the $P 6_{3} / \mathrm{m}$ space group and interplanar spacings of 5.2 and $2.0 \AA$, corresponding to the (100) and (201) planes, respectively; this revealed the highly crystalline nature of the $\mathrm{NaYF}_{4}: \mathrm{Yb}, \mathrm{Tm}$ nanocrystals (Fig. 2c). The selection area electron diffraction (SAED) pattern (Fig. 2e) also

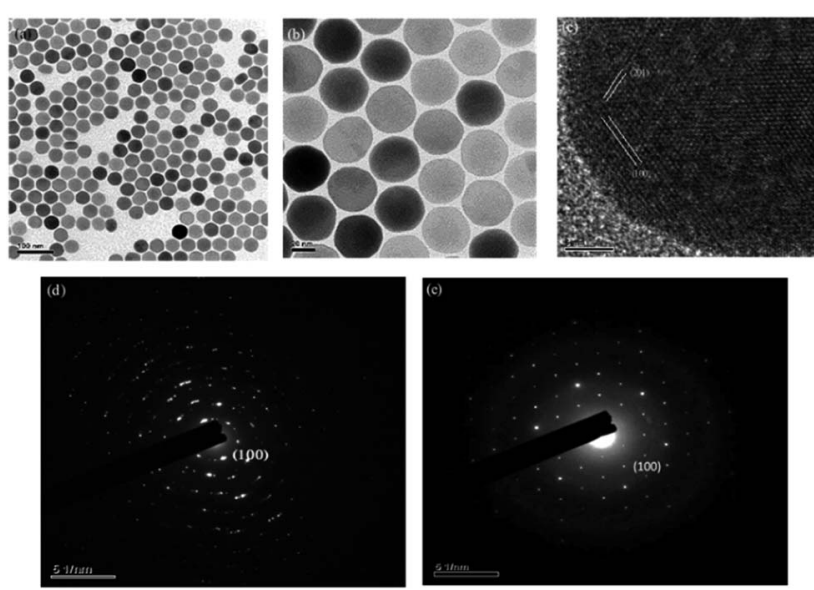

Fig. 2 TEM images of ( $a$ and b) $\mathrm{NaYF}_{4}: \mathrm{Yb}, \mathrm{Tm}(88 \% / 20 \% / 2 \%)$ upconversion nanocrystals; (c) HRTEM image; SAED patterns of the (d) $\mathrm{aYF}_{4}: \mathrm{Yb}, \mathrm{Tm}$ (78\%/20\%/2\%) upconversion nanocrystals and (e) $\mathrm{NaYF}_{4}: \mathrm{Yb}, \mathrm{Tm}(88 \% / 20 \% / 2 \%)$ upconversion nanocrystals. 


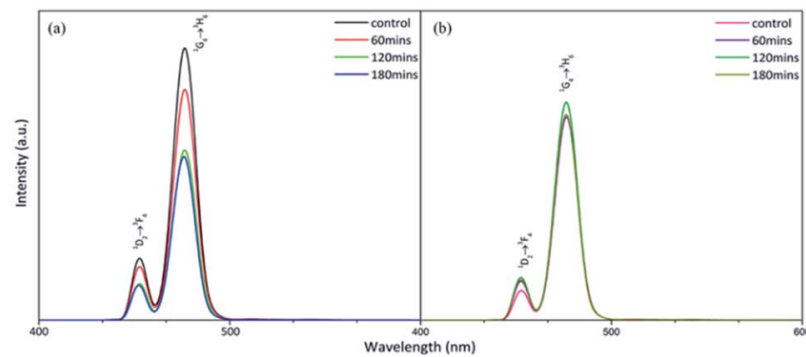

Fig. 3 Photoluminescence spectra of the two types of upconversion nanoparticles under a $980 \mathrm{~nm}$ excitation wavelength laser for $3 \mathrm{~h}$ (1.5 $\mathrm{W} \mathrm{cm}^{-2}$ ): (a) $\mathrm{NaYF}_{4}: \mathrm{Yb}_{1} \mathrm{Tm}(78 \% / 20 \% / 2 \%)$, (b) NaYF 4 :Yb,Tm $(88 \% /$ $20 \% / 2 \%)$

confirmed the crystal structure. The SAED pattern illustrated a regular arrangement of single crystals. Nanoparticles with $78 \% \mathrm{Y}^{3+}$ were defined as polycrystalline (Fig. 2d). Thus, upconversion nanoparticles can be synthesized with $88 \mathrm{~mol} \%$ of $\mathrm{Y}^{3+}$ ion without impurity.

To compare the fluorescence of the crystalline and polycrystalline materials, we used a photoluminescence spectrometer (PL) to record the patterns (Fig. 3). The results demonstrated that the fluorescence of $\mathrm{NaYF}_{4}: \mathrm{Yb}, \mathrm{Tm}(78 \% / 20 \% / 2 \%)$ decayed considerably after 60 minute irradiation by a $980 \mathrm{~nm}$ diode laser (Fig. 3a). In contrast, the fluorescence of $\mathrm{NaYF}_{4}: \mathrm{Yb}, \mathrm{Tm}(88 \% / 20 \% /$ $2 \%)$ did not decrease significantly after being irradiated with a $980 \mathrm{~nm}$ diode laser for $180 \mathrm{~min}$ (Fig. 3b). It can be seen that highquality pure hexagonal $\mathrm{NaYF}_{4}: \mathrm{Yb}, \mathrm{Tm}$ nanocrystals can extend the luminous lifetime of UCNPs.

In order to effectively avoid the thermal damage caused by the $980 \mathrm{~nm}$ NIR irradiation of the organism, the surface of the $\mathrm{NaYF}_{4}: \mathrm{Yb}, \mathrm{Tm}$ upconversion nanoparticles was coated with a layer of neodymium ( $\mathrm{Nd}$ ) element in this experiment so that the upconversion nanoparticles can be excited with an $808 \mathrm{~nm}$ laser to reduce thermal damage. However, this method increased the particle size of our upconversion nanoparticles to $95 \mathrm{~nm}$. Fang Lu's team confirmed that the uptake of cells with a particle size of $50 \mathrm{~nm}$ is about 5 times that of a carrier with a particle size of $100 \mathrm{~nm} .{ }^{53}$ Thus, large size is not conducive to subsequent transfection efficiency. In the future, we hope to directly synthesize $\mathrm{NaYF}_{4}: \mathrm{Yb}, \mathrm{Tm}, \mathrm{Nd}$ upconversion nanoparticles, which can not only reduce thermal damage but also improve transfection efficiency.

The SEM observation of the $\mathrm{NaYF}_{4}: \mathrm{Yb}, \mathrm{Tm}_{\mathrm{N}} @ \mathrm{NaYF}_{4}: \mathrm{Yb}, \mathrm{Nd}$ upconversion nanoparticles showed a particle size of about $95 \mathrm{~nm}$ (Fig. 4a and b) and hexagonal phase with the $P 6_{3} / m$ space group and interplanar spacings of 5.2 and $2.9 \AA$, which correspond to the (100) and (101) planes, respectively; this revealed the highly crystalline nature of the $\mathrm{NaYF}_{4}: \mathrm{Yb}, \mathrm{Tm} @ \mathrm{NaYF}_{4}: \mathrm{Yb}, \mathrm{Nd}$ upconversion nanoparticles (Fig. 4c). The selection area electron diffraction (SAED) pattern (Fig. 4d) also confirmed the crystal structure. The SAED pattern illustrated a regular arrangement of single crystals. Thus confirmed again that upconversion nanoparticles can be synthesized with $88 \mathrm{~mol} \%$ of $\mathrm{Y}^{3+}$ ion without impurity.

At present, there are three common modification methods for upconversion nanoparticles: the silylation method of coating the particle surface with a silica shell layer, the ligand
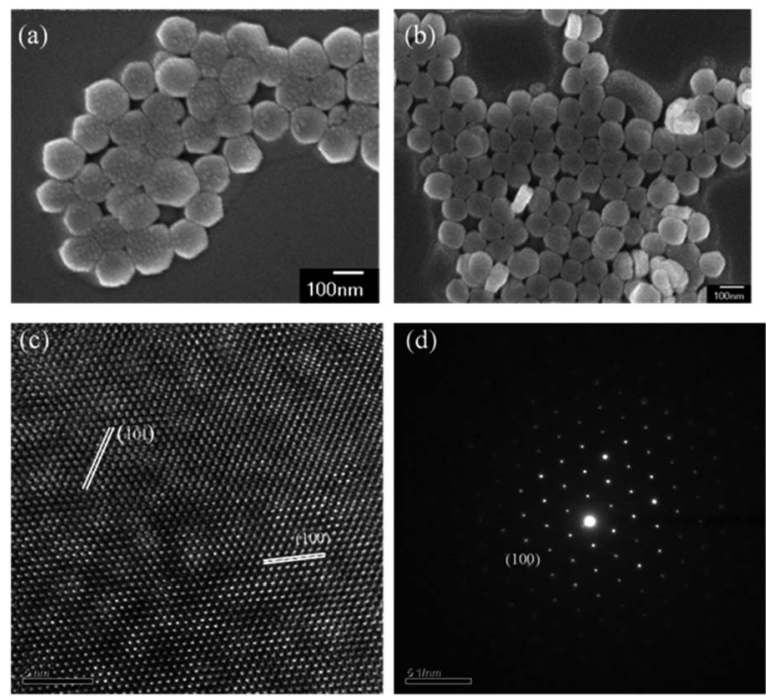

Fig. $4 \mathrm{SEM}$ images of (a and b) the $\mathrm{NaYF}_{4}: \mathrm{Yb}_{1} \mathrm{Tm}_{\mathrm{NaNaYF}}: \mathrm{Yb}, \mathrm{Nd}$ upconversion nanoparticles. TEM image (c) and HRTEM image (d) of the $\mathrm{NaYF}_{4}: \mathrm{Yb}_{\text {, TmaNaYF}}: \mathrm{Yb}_{4} \mathrm{Nd}$ upconversion nanoparticles with the SAED pattern.

exchange modification of substituting oleic acid, and the addition of other hydrophilic surface functional groups after oleic acid can all modify hydrophobic particles into hydrophilic particles, which can effectively reduce the surface quenching of UCNPs and increase their biocompatibility. In this experiment, we used surface modification to modify hydrophobic UCNPs into hydrophilic UCNPs. ${ }^{44,55}$

The mesoporous silica shell structure obtained by the sol-gel two-phase transfer strategy via surfactant modification can be obviously seen in Fig. 5 . The oleic acid-capped $\mathrm{NaYF}_{4}$ nanocrystal cores reacted with CTAB and TEOS. The TEM observation of the $\mathrm{NaYF}_{4}: \mathrm{Yb}, \mathrm{Tm} @ \mathrm{mSiO}_{2}$ upconversion nanoparticles shows a particle size of about $50 \mathrm{~nm}$ (Fig. 5a), and the TEM observation of the $\mathrm{NaYF}_{4}: \mathrm{Yb}, \mathrm{Tm} @ \mathrm{NaYF}_{4}: \mathrm{Yb}, \mathrm{Nd} @ \mathrm{mSiO}_{2}$ upconversion nanoparticles shows a particle size of about $100 \mathrm{~nm}$ (Fig. 5b).

The nanosphere materials were successfully transferred from organic to aqueous solutions. Images indicate that the nanocrystals exhibit uniform distributions, sizes, and shapes. The aggregation was attributed to the concentration of the surfactant and the volume of TEOS. Furthermore, the decrease of the CTAB concentration resulted in $\mathrm{NaYF}_{4}$ nanocrystal aggregation. However, after silication, the luminescence decreased. Thus, the organic groups influenced the luminescence intensity of the nanocrystals through photon relaxation.

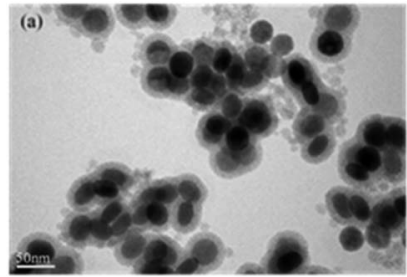

Fig. 5 TEM images of (a) $\mathrm{NaYF}_{4}: \mathrm{Yb}, \mathrm{Tm}_{\mathrm{NaNaYF}}: \mathrm{Yb}, \mathrm{NdamSiO} 2$

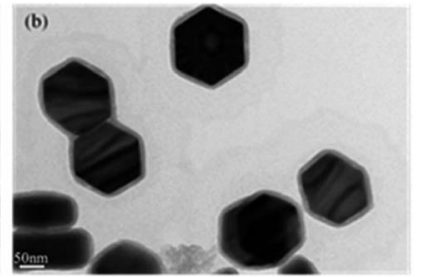

(a) $\mathrm{NaYF}_{4}: \mathrm{Yb}, \mathrm{TmamSiO}$ 


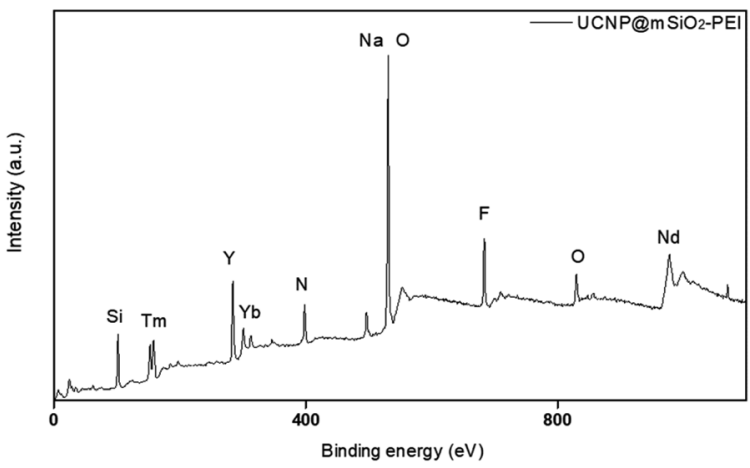

Fig. 6 XRD patterns of (a) NaYF 4 :Yb,Tm, (b) NaYF 4 :Yb,TmaNaYF 4 :$\mathrm{Yb}, \mathrm{Nd}$, (c) $\mathrm{NaYF}_{4}: \mathrm{Yb}, \mathrm{Tm}_{\mathrm{NaNaF}}: \mathrm{Yb}, \mathrm{Nd} \mathrm{amSiO} \mathrm{N}_{2}-\mathrm{NH}_{2}$, and (d) hexagonal phase (JCPDS standard card no. 16-0334).

The crystal structure of $\mathrm{NaYF}_{4}$ was determined through XRD. The powder XRD patterns in Fig. 6 are consistent with JCPDS card\# 16-0334; this result proved that the diffraction patterns indicated pure $\beta-\mathrm{NaYF}_{4}$ hexagonal phase and no other impurity diffraction peak. Therefore, it can be determined that the upconversion nanoparticles synthesized in this way are all single-crystal structures.

In addition, in order for the upconversion nanoparticles to successfully link with DNA, we modified a layer of an amine group on the outer layer of $\mathrm{UCNP} @ \mathrm{SiO}_{2}$ to endow the surface of the upconversion nanoparticles with a positive charge and successfully link the negatively charged DNA. The element composition of an amine group was measured through XPS (Fig. 7). Also, XRD was used to confirm the crystal structures of the upconversion nanoparticles with modified amine groups. It can be confirmed from Fig. 6 that the modification process did not affect the crystal structure of $\mathrm{NaYF}_{4}$.

We used zeta potential measurements to confirm the potentials of the modified upconversion nanoparticles. From Fig. 8a, we can see that the upconversion nanoparticles were negatively charged after being modified on the silicon shell. After modifying the amine groups, the positive charge of the mesoporous

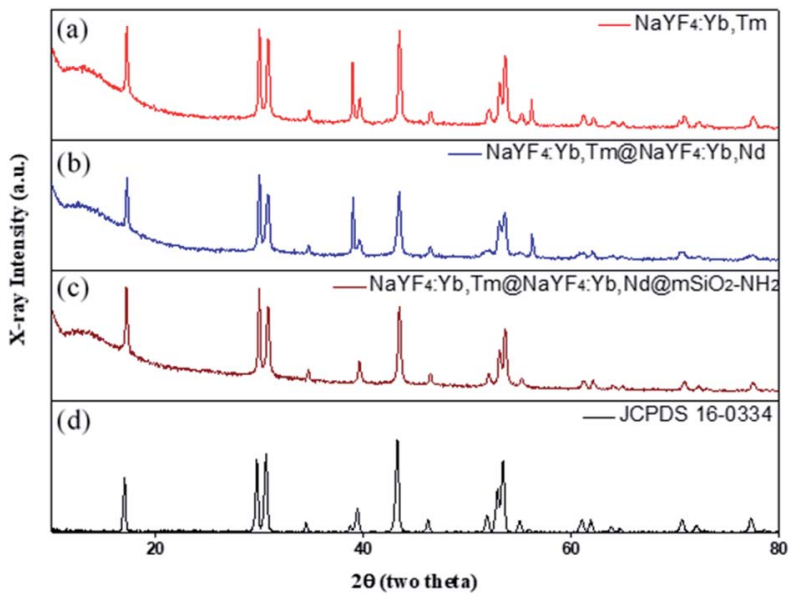

Fig. 7 XPS pattern of UCNPamSiO 2 -PEI.
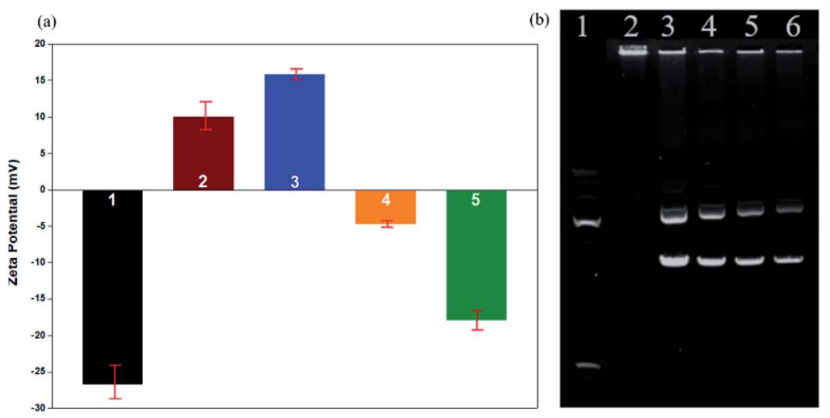

Fig. 8 (a) Zeta potentials of 1. UCNPASiO 2 , 2. UCNP@SiO ${ }_{2}-\mathrm{NH}_{2}, 3$. UCNP@mSiO $2-\mathrm{NH}_{2}, 4$. DNA-UCNP, 5. DNA. The error bars indicate means \pm S.D. $(n=4)$. (b) Gel electrophoresis of the DNA-UCNPs. 1. DNA marker, 2. UCNPs/DNA prepared at a w/w ratio of $10: 2.3$. UCNPs/DNA prepared at a w/w ratio of $10: 3$. 4. UCNPs/DNA prepared at a $w / w$ ratio of $10: 4$. 5. DNA $(12 \mu \mathrm{L}), 6$. DNA $(10 \mu \mathrm{L})$.

silica shell was higher than that of the silicon shell. In addition, because DNA is negatively charged, UCNPs modified with DNA are slightly negatively charged. As a result of the zeta potential changing from a positive potential to a negative potential, it was confirmed that DNA was successfully linked to the UCNPs.

Gel electrophoresis is affected by charge, molecular weight, and isoelectric point. In the gel electrophoresis, as shown in Fig. $8 \mathrm{~b}$, when the UCNPs/DNA ratio was $10: 3$ or $10: 4(\mathrm{w} / \mathrm{w})$, there were two bright bands in addition to the first bright band; we judged these bands to be free circular DNA and supercoiled DNA, which indicates that some DNA was not connected to the UCNPs. When the UCNP/DNA ratio was $10: 2(\mathrm{w} / \mathrm{w})$, these two bright bands did not appear. We judged that no free DNA flowed out from the sample well, and only DNA-UCNPs remained in the sample well. Therefore, the optimal ratio of UCNPs/DNA is $10: 2(\mathrm{w} / \mathrm{w})$.

In order to evaluate the transfection efficiency of the upconversion nanoparticles, we used a fluorescence microscope and flow cytometry to observe transfection efficiency of the amino group and plasmid DNA modifications in the mesoporous silica shell of the particles. Channelrhodopsin-2 (ChR2) light-sensitive channel protein is a membrane protein. Under microscopy, a layer of membrane can be found around the periphery of cardiomyocytes (Fig. 9d). pcDNA3.1/hChR2(H134R)-mCherry contains mCherry fragments; thus, it will emit red fluorescence under microscopy.

By this result, it can be determined that the DNA successfully entered the cells and was transfected. The results showed that the mCherry signal from the DNA was detected in the primary cells by fluorescence microscopy (Fig. 9b), indicating that the DNA-UCNPs have transfection ability. From the results of the flow cytometry (Fig. 9c), we can observe that the transfection efficiency of $\mathrm{NaYF}_{4}: \mathrm{Yb}, \mathrm{Tm} @ \mathrm{mSiO}_{2}-\mathrm{NH}_{2}$-DNA is very high. Compared with traditional linear virus transfection, adenovirus transfection efficiency is as high as 93\% (Fig. 10). However, DNA-UCNPs can also achieve 78\% efficiency (Fig. 10). Therefore, the current research proves that UCNPs are very effective in delivering DNA safely and effectively. This is expected to replace adenovirus transfection methods in the future.

It can be seen in Fig. 10 that the transfection efficiency of the mesoporous silica shell of UCNPs is higher than that of the 

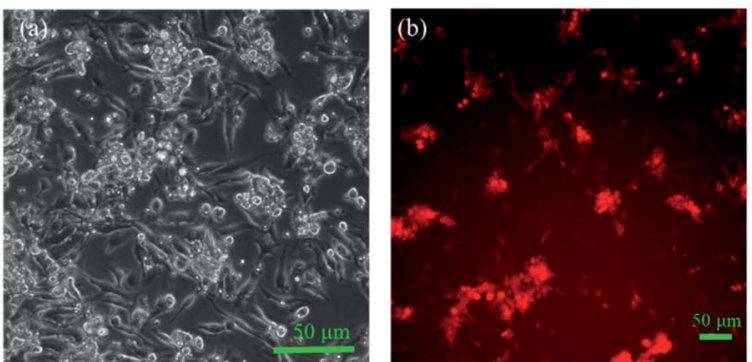

(c) All
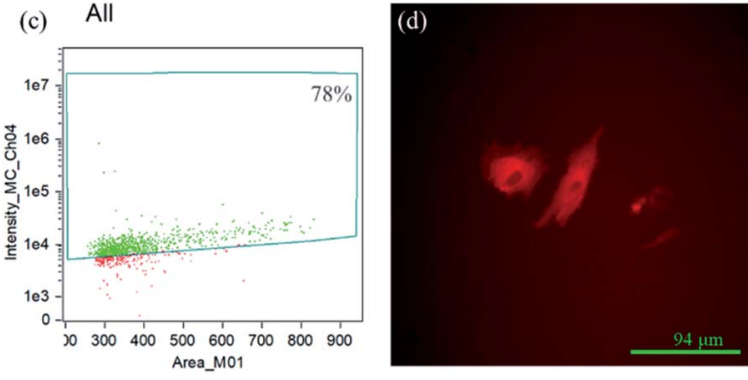

Fig. 9 Primary cells after incubation with UCNPamSiO $-\mathrm{NH}_{2}-\mathrm{DNA}$ for $48 \mathrm{~h}$. (a) Bright field and (b) fluorescence microscope images, $\lambda_{\mathrm{ex}}=$ $587 \mathrm{~nm}$, and emissions were collected in the range of $\lambda=610 \mathrm{~nm}$. (c) Transfection efficiency of UCNPamSiO $2-\mathrm{NH}_{2}$-DNA through flow cytometry. (d) High-magnification image of primary cells after transfection.

silica shell of UCNPs. In addition, the transfection efficiency of the $\mathrm{NaYF}_{4}: \mathrm{Yb}, \mathrm{Tm}$ upconversion nanoparticles is also higher than the larger $\mathrm{NaYF}_{4}: \mathrm{Yb}, \mathrm{Tm} @ \mathrm{NaYF}_{4}: \mathrm{Yb}, \mathrm{Nd}$ upconversion nanoparticles. These results indicate the particle size and whether the etching will affect the transfection efficiency of the final upconversion nanoparticles.

To evaluate the possible cytotoxicity of UCNP@ $\mathrm{mSiO}_{2}$, the cell metabolic activity was verified using the MTT method in primary cardiac myoblast cells; the results indicated that the upconversion nanoparticles have lower cytotoxicity after modification. The cell metabolic activity was not hindered by UCNP@mSiO

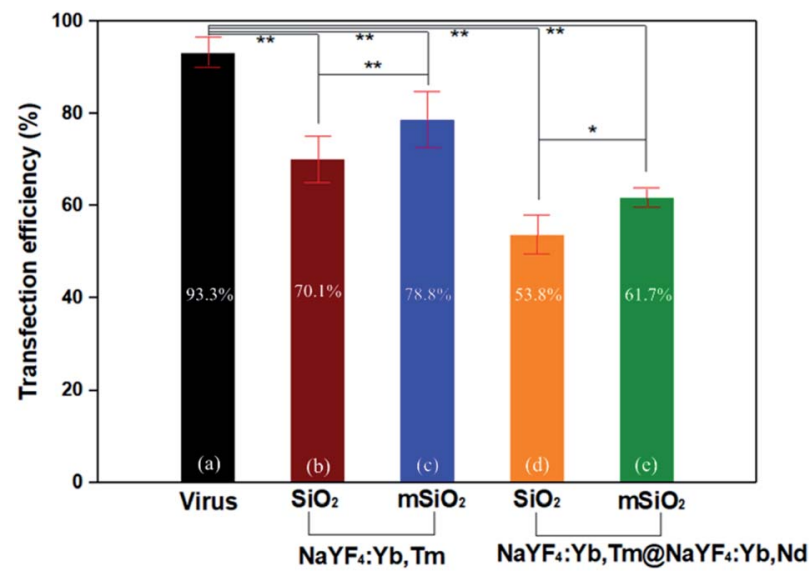

Fig. 10 Transfection efficiencies of (a) virus, (b) $\mathrm{NaYF}_{4}: \mathrm{Yb}_{1} \mathrm{TmaSiO}_{2}-$ $\mathrm{NH}_{2}$-DNA, (c) $\mathrm{NaYF}_{4}: \mathrm{Yb}_{1}, \mathrm{TmamSiO}_{2}-\mathrm{NH}_{2}-\mathrm{DNA}$, (d) $\mathrm{NaYF}_{4}$ :$\mathrm{Yb}, \mathrm{TmaNaYF}$ : $\mathrm{Yb}, \mathrm{Nd} \mathrm{NSiO}{ }_{2}-\mathrm{NH}_{2}-\mathrm{DNA}$, and (e) NaYF 4 :$\mathrm{Yb}, \mathrm{TmaNaYF}_{4}: \mathrm{Yb}, \mathrm{NdamSiO} \mathrm{N}_{2}-\mathrm{NH}_{2}-\mathrm{DNA}$. The error bars indicate means \pm S.D. $(n=6) . *: p<0.05, * *: p<0.01$.

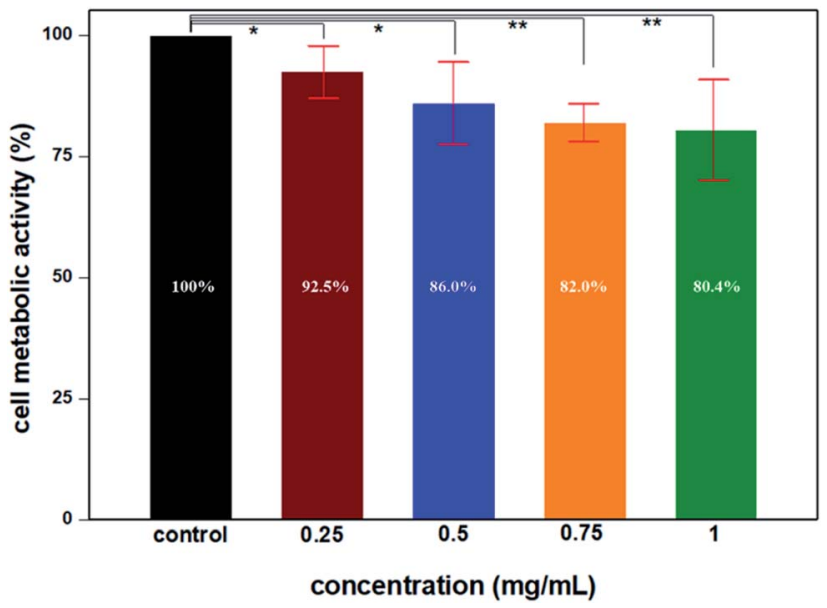

Fig. 11 Cell metabolic activities of UCNPamSiO $2-\mathrm{NH}_{2}$ through the MTT assay of primary cells. At all the test concentrations of UCNPs, the cell metabolic activity is higher than $80 \%$. The error bars indicate means \pm S.D. $(n=8)$. *: $p<0.05, * *: p<0.01$.

at high concentrations. The results depicted in Fig. 11 indicate that the cell metabolic activities of different concentrations of UCNP@ $@ \mathrm{mSiO}_{2}$ were more than $80 \%$ after incubation for $48 \mathrm{~h}$, which shows that UCNP@mSiO $\mathrm{m}_{2}$ has great biocompatibility at high concentrations and long incubation times.

\section{Conclusions}

In this study, we used a user-friendly coprecipitation method and increased the amount of $\mathrm{Y}^{3+}$ ion to $88 \mathrm{~mol} \%$ to synthesize high-quality pure hexagonal-phase $\mathrm{NaYF}_{4}$ nanoparticles with controllable shapes and strong fluorescence. $\beta-\mathrm{NaYF}_{4}$ can not only improve the luminous intensity of the upconversion nanoparticles but can also effectively extend their luminous lifetime. In order to effectively improve the biological application of upconversion nanoparticles, modifying a silicon shell on the surface of the upconversion nanoparticles not only effectively improves the hydrophobicity of the upconversion nanoparticles but also endows them with good biocompatibility.

Upconversion nanoparticles modified with amine groups can effectively bind to DNA, and DNA-UCNPs with smaller particles have good transfection efficiency. The DNA-UCNPs we developed provide an alternative method to the traditional adenovirus for transfection and can provide the best UCNPs for materials science and biology.

\section{Ethical statement}

All animal procedures were performed in accordance with the Guidelines for Care and Use of Laboratory Animals of National Chiao Tung University and approved by the Animal Ethics Committee of Institutional Animal Care and Use Committee (IACUC).

\section{Conflicts of interest}

There are no conflicts to declare. 


\section{Notes and references}

1 Q. Q. Dou, H. C. Guo and E. Ye, Near-infrared upconversion nanoparticles for bio-applications, Mater. Sci. Eng., C, 2014, 45, 635-643.

2 H. Zou, F. Jin, X. Song and J. Xing, Singlet oxygen generation of photosensitizers effectively activated by $\mathrm{Nd}^{3+}$-doped upconversion nanoparticles of luminescence intensity enhancing with shell thickness decreasing, Appl. Surf. Sci., 2017, 400, 81-89.

3 X. Wu, P. Hu, S. Hu, Z. Chen, H. Yan, Z. Tang, Z. Xi, Y. Yu, G. Dai and Y. Liu, Upconversion nanoparticles for differential imaging of plant cells and detection of fluorescent dyes, J. Rare Earths, 2016, 34(2), 208-220.

4 E. Hemmer, P. Acosta-Mora, J. Méndez-Ramos and S. Fischer, Optical nanoprobes for biomedical applications: shining a light on upconverting and near-infrared emitting nanoparticles for imaging, thermal sensing, and photodynamic therapy, J. Mater. Chem. B, 2017, 5(23), 4365-4392.

5 X. Liu, M. Liu, J. Chen, Z. Li and Q. Yuan, Rational design and biomedical applications of DNA-functionalized upconversion nanoparticles, Chin. Chem. Lett., 2018, 29(9), 1321-1332.

6 V. Muhr, C. Würth, M. Kraft, M. Buchner, A. J. Baeumner, U. Resch-Genger and T. Hirsch, Particle-size-dependent Forster resonance energy transfer from upconversion nanoparticles to organic dyes, Anal. Chem., 2017, 89(9), 4868-4874.

7 S. Wilhelm, Perspectives for upconverting nanoparticles, ACS Nano, 2017, 11(11), 10644-10653.

8 H. Dong, L.-D. Sun and C.-H. Yan, Energy transfer in lanthanide upconversion studies for extended optical applications, Chem. Soc. Rev., 2015, 44(6), 1608-1634.

9 Z. Zhu, D. Tian and X. Shu, Auto-phase-locked time-gated luminescence detection for background-free upconversion spectra measurement and true-color biological imaging, Sens. Actuators, B, 2018, 260, 289-294.

10 H. LiáJo, Y. HanáSong and K. TaekáLee, Fast and background-free three-dimensional (3D) live-cell imaging with lanthanide-doped upconverting nanoparticles, Nanoscale, 2015, 7(46), 19397-19402.

11 A. Bagheri, H. Arandiyan, C. Boyer and M. Lim, LanthanideDoped Upconversion Nanoparticles: Emerging Intelligent Light-Activated Drug Delivery Systems, Adv. Sci., 2016, 3(7), 1500437.

12 S. S. Lucky, N. M. Idris, K. Huang, J. Kim, Z. Li, P. S. P. Thong, R. Xu, K. C. Soo and Y. Zhang, In vivo biocompatibility, biodistribution and therapeutic efficiency of titania coated upconversion nanoparticles for photodynamic therapy of solid oral cancers, Theranostics, 2016, 6(11), 1844.

13 J. Peng, W. Xu, C. L. Teoh, S. Han, B. Kim, A. Samanta, J. C. Er, L. Wang, L. Yuan and X. Liu, High-efficiency in vitro and in vivo detection of $\mathrm{Zn}^{2+}$ by dye-assembled upconversion nanoparticles, J. Am. Chem. Soc., 2015, 137(6), 2336-2342.
14 X. Bai, S. Xu, J. Liu and L. Wang, Upconversion luminescence tracking of gene delivery via multifunctional nanocapsules, Talanta, 2016, 150, 118-124.

15 T. Cao, Y. Yang, Y. Gao, J. Zhou, Z. Li and F. Li, High-quality water-soluble and surface-functionalized upconversion nanocrystals as luminescent probes for bioimaging, Biomaterials, 2011, 32(11), 2959-2968.

16 M. H. Chan, Y. T. Pan, I. J. Lee, C. W. Chen, Y. C. Chan, M. Hsiao, F. Wang, L. Sun, X. Chen and R. S. Liu, Minimizing the Heat Effect of Photodynamic Therapy Based on Inorganic Nanocomposites Mediated by $808 \mathrm{~nm}$ Near-Infrared Light, Small, 2017, 13, 1700038.

17 A. Sedlmeier and H. H. Gorris, Surface modification and characterization of photon-upconverting nanoparticles for bioanalytical applications, Chem. Soc. Rev., 2015, 44(6), 1526-1560.

18 C. Liu, Z. Wang, X. Wang and Z. Li, Surface modification of hydrophobic $\mathrm{NaYF}_{4}: \mathrm{Yb}$,Er upconversion nanophosphors and their applications for immunoassay, Sci. China: Chem., 2011, 54(8), 1292.

19 Y. Tang, W. Di, X. Zhai, R. Yang and W. Qin, NIR-responsive photocatalytic activity and mechanism of $\mathrm{NaYF}_{4}: \mathrm{Yb}, \mathrm{Tm} @$ $\mathrm{TiO}_{2}$ core-shell nanoparticles, ACS Catal., 2013, 3(3), 405412.

20 L. Fenno, O. Yizhar and K. Deisseroth, The development and application of optogenetics, Annu. Rev. Neurosci., 2011, 34, 389-412.

21 A. Ahmad, S. Ashraf and S. Komai, Optogenetics applications for treating spinal cord injury, Asian Spine J., 2015, 9(2), 299305.

22 C. M. Ambrosi, P. M. Boyle, K. Chen, N. A. Trayanova and E. Entcheva, Optogenetics-enabled assessment of viral gene and cell therapy for restoration of cardiac excitability, Sci. Rep., 2015, 5, 17350.

23 U. Nussinovitch and L. Gepstein, Optogenetics for in vivo cardiac pacing and resynchronization therapies, Nat. Biotechnol., 2015, 33(7), 750-754.

24 S. A. Park, S.-R. Lee, L. Tung and D. T. Yue, Optical mapping of optogenetically shaped cardiac action potentials, Sci. Rep., 2014, 4, 6125.

25 Q. Li, R. Ni, H. Hong, K. Y. Goh, M. Rossi, V. G. Fast and L. Zhou, Electrophysiological Properties and Viability of Neonatal Rat Ventricular Myocyte Cultures with Inducible ChR2 Expression, Sci. Rep., 2017, 7(1), 1531.

26 K. P. Gerhardt, E. J. Olson, S. M. Castillo-Hair, L. A. Hartsough, B. P. Landry, F. Ekness, R. Yokoo, E. J. Gomez, P. Ramakrishnan and J. Suh, An openhardware platform for optogenetics and photobiology, Sci. Rep., 2016, 6, 35363.

27 G. P. Pathak, J. D. Vrana and C. L. Tucker, Optogenetic control of cell function using engineered photoreceptors, Biol. Cell, 2013, 105(2), 59-72.

28 D. M. Shcherbakova, A. A. Shemetov, A. A. Kaberniuk and V. V. Verkhusha, Natural photoreceptors as a source of fluorescent proteins, biosensors, and optogenetic tools, Annu. Rev. Biochem., 2015, 84, 519-550. 
29 Y.-C. Chen, W.-T. Chiu, J.-C. Chen, C.-S. Chang, L. H.-C. Wang, H.-P. Lin and H.-C. Chang, The photothermal effect of silica-carbon hollow sphereconcanavalin A on liver cancer cells, J. Mater. Chem. B, 2015, 3(12), 2447-2454.

30 H. Guo, R. Hao, H. Qian, S. Sun, D. Sun, H. Yin, Z. Liu and $\mathrm{X}$. Liu, Upconversion nanoparticles modified with aminosilanes as carriers of DNA vaccine for foot-andmouth disease, Appl. Microbiol. Biotechnol., 2012, 95(5), 1253-1263.

31 R. Lv, D. Yang, P. Yang, J. Xu, F. He, S. Gai, C. Li, Y. Dai, G. Yang and J. Lin, Integration of upconversion nanoparticles and ultrathin black phosphorus for efficient photodynamic theranostics under $808 \mathrm{~nm}$ near-infrared light irradiation, Chem. Mater., 2016, 28(13), 4724-4734.

32 S. Stolik, J. Delgado, A. Perez and L. Anasagasti, Measurement of the penetration depths of red and near infrared light in human "ex vivo" tissues, J. Photochem. Photobiol., B, 2000, 57(2-3), 90-93.

$33 \mathrm{~S}$. Wu and H. J. Butt, Near-infrared-sensitive materials based on upconverting nanoparticles, Adv. Mater., 2016, 28(6), 1208-1226.

34 S. S. Lucky, N. Muhammad Idris, Z. Li, K. Huang, K. C. Soo and Y. Zhang, Titania coated upconversion nanoparticles for near-infrared light triggered photodynamic therapy, ACS Nano, 2015, 9(1), 191-205.

35 N. G. A. Tan, W. Wu and A. M. Seifalian, Optogenetics: lights, camera, action! A ray of light, a shadow unmasked, in Applications of Nanoscience in Photomedicine, Chandos Publishing, 2015, pp. 185-203.

36 S. Kasparov, Optogenetics, in Primer on the Autonomic Nervous System, Academic Press, 2012, pp. 689-691.

$37 \mathrm{X}$. Huang, Realizing efficient upconversion and downshifting dual-mode luminescence in lanthanide-doped $\mathrm{NaGdF}_{4}$ core-shell-shell nanoparticles through gadolinium sublattice-mediated energy migration, Dyes Pigm., 2016, 130, 99-105.

38 H. Dong, L.-D. Sun, Y.-F. Wang, J. Ke, R. Si, J.-W. Xiao, G.-M. Lyu, S. Shi and C.-H. Yan, Efficient Tailoring of Upconversion Selectivity by Engineering Local Structure of Lanthanides in $\operatorname{NaxREF}^{3+}$ x Nanocrystals, J. Am. Chem. Soc., 2015, 137(20), 6569-6576.

39 S. Wen, J. Zhou, K. Zheng, A. Bednarkiewicz, X. Liu and D. Jin, Advances in highly doped upconversion nanoparticles, Nat. Commun., 2018, 9(1), 2415.

40 E. M. Chan, E. S. Levy and B. E. Cohen, Rationally designed energy transfer in upconverting nanoparticles, Adv. Mater., 2015, $27(38)$, 5753-5761.

41 D. T. Klier and M. U. Kumke, Analysing the effect of the crystal structure on upconversion luminescence in $\mathrm{Yb}^{3+}$, $\mathrm{Er}^{3+}$-co-doped $\mathrm{NaYF}_{4}$ nanomaterials, J. Mater. Chem. C, 2015, 3(42), 11228-11238.

42 J. Suyver, A. Aebischer, D. Biner, P. Gerner, J. Grimm, S. Heer, K. Krämer, C. Reinhard and H.-U. Güdel, Novel materials doped with trivalent lanthanides and transition metal ions showing near-infrared to visible photon upconversion, Opt. Mater., 2005, 27(6), 1111-1130.

43 Y. Tian, B. Tian, P. Huang, L. Wang and B. Chen, Sizedependent upconversion luminescence and temperature sensing behavior of spherical $\mathrm{Gd}_{2} \mathrm{O}_{3}: \mathrm{Yb}^{3+} / \mathrm{Er}^{3+}$ phosphor, RSC Adv., 2015, 5(19), 14123-14128.

44 H. Lu, G. Yi, S. Zhao, D. Chen, L.-H. Guo and J. Cheng, Synthesis and characterization of multi-functional nanoparticles possessing magnetic, up-conversion fluorescence and bio-affinity properties, J. Mater. Chem., 2004, 14(8), 1336-1341.

45 H. S. Mader, P. Kele, S. M. Saleh and O. S. Wolfbeis, Upconverting luminescent nanoparticles for use in bioconjugation and bioimaging, Curr. Opin. Chem. Biol., 2010, 14(5), 582-596.

46 D. Zhao, Q. Huo, J. Feng, B. F. Chmelka and G. D. Stucky, Nonionic triblock and star diblock copolymer and oligomeric surfactant syntheses of highly ordered, hydrothermally stable, mesoporous silica structures, J. Am. Chem. Soc., 1998, 120(24), 6024-6036.

47 I. I. Slowing, J. L. Vivero-Escoto, C.-W. Wu and V. S.-Y. Lin, Mesoporous silica nanoparticles as controlled release drug delivery and gene transfection carriers, Adv. Drug Delivery Rev., 2008, 60(11), 1278-1288.

48 F. Wang, J. Wang and X. Liu, Direct evidence of a surface quenching effect on size-dependent luminescence of upconversion nanoparticles, Angew. Chem., Int. Ed., 2010, 49(41), 7456-7460.

49 J. Yu, W. Yin, T. Peng, Y. N. Chang, Y. Zu, J. Li and Y. Zhao, Biodistribution, excretion, and toxicity of polyethyleneimine modified $\mathrm{NaYF}_{4}: \mathrm{Yb}$,Er upconversion nanoparticles in mice via different administration routes, Nanoscale, 2017, 9(13), 4497-4507.

50 O. Yizhar, L. E. Fenno, T. J. Davidson, M. Mogri and K. Deisseroth, Optogenetics in neural systems, Neuron, 2011, 71(1), 9-34.

51 B. Sibbald, Death but one unintended consequence of genetherapy trial. Canadian Medical Association, Journal, 2001, 164(11), 1612.

52 K. L. Douglas, Toward development of artificial viruses for gene therapy: A comparative evaluation of viral and non-viral transfection, Biotechnol. Prog., 2008, 24(4), 871883.

53 F. Lu, S. H. Wu, Y. Hung and C. Y. Mou, Size effect on cell uptake in well-suspended, uniform mesoporous silica nanoparticles, Small, 2009, 5(12), 1408-1413.

54 K. Yadav, A. C. Chou, R. K. Ulaganathan, H. D. Gao, H. M. Lee, C. Y. Pan and Y. T. Chen, Targeted and efficient activation of channel rhodopsins expressed in living cells via specifically-bound upconversion nanoparticles, Nanoscale, 2017, 9(27), 9457-9466.

55 A. Sedlmeier and H. H. Gorris, Surface modification and characterization of photon-upconverting nanoparticles for bioanalytical applications, Chem. Soc. Rev., 2015, 44(6), 1526-1560. 